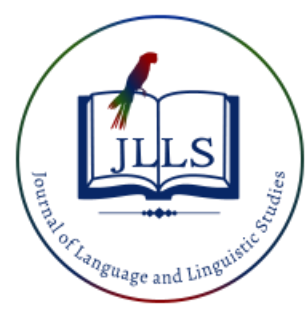

Available online at www.jlls.org

JOURNAL OF LANGUAGE

AND LINGUISTIC STUDIES

ISSN: 1305-578X

Journal of Language and Linguistic Studies, 17(1), 173-186; 2021

\title{
Corpus analysis in abstracts' Ph.D. students in the USA: A case study
}

\author{
Suna Kunghair a iD, Chaleomkiet Yenphech b ${ }^{\text {iD }}$ \\ ${ }^{a}$ Mahachulalongkornrajavidhayalaya University, Thailand \\ ${ }^{b}$ Mahachulalongkornrajavidhayalaya University, Thailand
}

\section{APA Citation:}

Kunghair, S., \& Yenphech, C. (2021). Corpus analysis in abstracts' Ph.D. students in the USA: A case study. Journal of Language and Linguistic Studies, 17(1), 173-186. Doi: 10.52462/jlls.10

Submission Date: 03/01/2021

Acceptance Date: 12/03/2021

\begin{abstract}
The aims of this study were 1) To identify the general description of the frequency of use of DMs (adding something) in the Thesis' Abstracts of Ph.D. writing, and 2) To investigate the relationship between the numbers of DMs (adding something) contribute in the Thesis' Abstracts of Ph.D. writing. The quantitative and qualitative in discourse markers (DMs) focused on the type of adding type i.e. moreover; in additionally; further; furthermore; further to this; also; besides; and what is more used in the educational theses' abstracts. This investigation examinations 108 abstracts works in the field of education were chosen by purposive sampling from American top-ranking universities. It intended to analyze the relations between the use of DMs, and their functions in the abstracts. The study also identified some qualifications that characterize a Ph.D. Students' writing expertise on DMs selection and use. The key finding has been that learners use a range of discourse markers, some of which are more popularly used than most others. There are lots of DMs (adding), the writers used only some of them when writing the abstracts. Some words were determined as DMs, but the functions were not DMs because they were not at the initial position. "In addition" markers were the most commonly used, abided by "Furthermore" markers. Analysis of the papers suggests guiding results for further research on developing abstracts writing quality.
\end{abstract}

Keywords: Corpus; Discourse Marker; Frequency; Writing quality; DMs

\section{Introduction}

When writing English for whatever purpose, the fundamental importance is the writing mechanism in English known as 'Mechanics of Writing' such as using conjunctions so that sentences, and paragraphs continue to flow smoothly. The use of grammar in order to write compact sentences using punctuation to help properly organize the text. As well as the use of spelling and capitalization to help each word. Which is a subset of the structure of the message that conveys better, and more clearly (Sukhothai Thammathirat Open University, 2005).

The abstract would be the most fundamental part recorded as a hard copy of a proposition since it resembles the main way to open your work to people in general. The abstract, particularly for scholarly investigation, should be short and evident to introduce the data of the examination. In this way, it may

\footnotetext{
${ }^{1}$ Corresponding author.

E-mail address: chaleomkiet.yp@bru.ac.th
} 
not be simple and the authors need handy composing methodologies and adequate semantic information.

Discourse markers have a few different names for example, 'Sentence connectives' (Halliday \& Hasan, 1976: 267), or 'Talk particles' (Aijmer, 2002; Schourup, 1985), or 'Expression particles' (Luke, 1990) or 'Semantic conjuncts' (Quirk, Greemhaum, Leech \& Svartvik, 1985) or 'Logical articulations' (Erman, 1987) or 'Talk administrators' (Redeker, 1991) or 'Continuatives' (Romero, 1997) or 'Talk connectives.' (Blakemore, 1987 and 1992) where 'Discourse markers' are the most well-known (Carter \& McCarthy, 2006; Fraser, 1999).

Discourse markers assume a vital function in controlling members' understanding in a progressing discussion (Lenk, 1998). Then Discourse Marker (DM), an important element of writing, needs to be integrated skillfully when writing abstracts. Several types of DM function differently in the writing discourse. Also, there are many forms of DM in each type. Indeed, it can not only make the abstracts become interesting and smooth, but also show the writing proficiencies of the writers.

Each year, there are a lot of researches were published worldwide. The abstracts of these researches would be the most accessible part for all researchers. These abstracts may also influence others, especially novice researchers, either the writing organization or the word used because they are alike the models. However, it was rarely found that many studies investigated the writing discourse in the published abstracts. Consequently, this study could be the starting point to review the writing discourse in the abstracts published worldwide. Whereupon, the important benefit to the knowledge of Discourse markers is that it makes writing easier for authors to understand, faster, and more accurate. This is because Discourse markers can help the author in various matters (Vivian, 1969: 295).

\subsection{Literature review}

The Corpus and Discourse arrangement consists of two lines. Core research in the corpus, discourse also underscores the imaginative commitment to different parts of linguistics, the corpus, a wide range of uses, from language innovations through second language literacy to the past is full of thoughts. The subsequent strand, studies in corpus and discourse is included key writings overcoming any issues between studies and linguistics. Albeit similarly scholastically thorough, this strand will be focused on a more extensive crowd of scholastics and postgraduate understudies working in the two orders (Mari, et. al., 2010). In the field of scholarly discussion, specialists need to share their findings with the rest of the local area. There are different methods of this correspondence. Research articles and papers are among them the main sources of scholarly correspondence (Aziz et. al., 2021).

\subsubsection{The Different Discourse Markers}

Discourse marker discovery has been in central trouble since late. To begin with, the compilation of the semantic list appears to stand in the way of an approach that seeks to reflect formal properties, although the arrangement of discourse marks includes a subset of the talking particles, which are much simpler set in the appropriate conditions (Csilla, 2010).

Fraser (1990) calls attention to that the investigation of DMs has transformed into a development industry over the most recent ten years. Many articles show up yearly zeroing in on nature, which means, and capacity of DMs. Fraser (1990) explores the previous exploration and infers that there was no strict understanding of DMs. It specifies a beginning mention by Levinson (1983:87-88) that takes into consideration DMs to be a category of phonetic articulations interesting and important from his own privileges. 
Schiffrin (1987: 49) allows DMs to focus on various stages of talking structures (linguistic or nonlinguistic). They can work in a 'thought' structure (giving advice) when they demonstrate their correlation between ideas in a talk, or hence they mark the association of ideas in discourses.

\subsubsection{Attributes of DMs}

In the accompanying segment, the highlights most ordinarily ascribed to DMs are distinguished and quickly examined starting with those highlights most generally alluded to:

\section{Interconnection}

Another of the features of DMs would be the use of each other to link representations or other discourse units. Hansen contains the definition of the DMs as "the orthography of the higher threshold and the sufficient professionalism is the correlation" (1998: 160).

\section{Flexibility}

DMs are regularly professed to be discretionary in two unmistakable faculties. They are viewed as linguistic judgments, as in immigration, the DMs would not rearrange the recipient sentence syntax. Nevertheless, DMs are often generally accepted as discretionary users in the sense that they do not increase their chances for semantic connection between allied components. Along these lines, if a DM is ignored, the connection that alone indicates is still accessible to both the listener, however not, at this point expressly prompted (Fraser, 1988: 22).

\section{Non-truth-restriction}

DMs are by and large ideas to contribute nothing to reality states of the recommendation communicated by an expression (Blakemore, 1988; Fraser, 1996: 167). Some interpret this as meaning that DMs don't influence the reality states of sentences. However, advocacy has evolved to show that the conditional reality is not related to the sentence. Rather, it is a psychological description (Blakemore, 1987: 16; Kempson et. al., 2001: 102).

Along these lines, discourse markers are words or expressions - despite the fact that they are linguistic units themselves - that capacity to flag how the current expression identifies with earlier discourse, likewise adding to the significance of the message. They are best acknowledged by being utilized toward the start of conditions. Taking into account that, a starter rundown of discourse markers can be determined, as far as their capacities, as follows (Dülger, 2007: 261).

1. Focusing And Linking: With reference to, Speaking/ Talking of / about, Regarding, As regards, With regard to, With respect to, In regard to, As to, As for 2) Contrasts: 2.1) Direct Contrast: However, Nevertheless, Mind you, Yet/Still/In spite of, Conversely, In contrast, In contrast to 2.2) Concession and Counter Argument: It is true, Of course, If, May, But, However, Even so, Nevertheless, Nonetheless, All the same, Still 2.3) Contradicting: On the country 2.4) Balancing Contrasting Points: While, On the other hand, Whereas 2.5) Dismissal of Previous Discourse: Anyway, At least, At any rate 3) Similarly: Similarly, In the same way, Likewise, By the same token 4) Change of Subject: By the way, Incidentally, Right, Now, O.K. 5) Structuring: First (ly), First of all, Second (ly), Third (ly), Lastly, Finally, To begin with, To start with, In the first/second/third place, For on thing, For another thing 6) Adding: Moreover, Further, Furthermore, In addition, As well as that, On top of that, Another thing, What is more, Besides, In any case, Also 7) Generalizing: On the whole, In general, In all/most/ many/some cases, Broadly speaking, By and large, To a great extent, Apart from, Except for.... 8) Exemplification: For instance, For example, In particular, Such as, e.g. 9) Logical Consequence: Thus, Hence, Accordingly, Therefore, As a result, Consequently, So, Then, That's why 10) Making Things Clear/ Softening and Correcting: I mean, Actually, That is to say, In other words, I think, I feel, I reckon, I guess, In my view/opinion, Apparently, So to speak, More or less, Sort of, Kind of Well, Really, At least, I am afraid, I suppose 11) Gaining Time: Let me see, Let's see, Well You know, I don't know, I mean, Kind of, Sort of 12) Showing One's Attitude to What One Is Saying: Honestly, Frankly, No doubt 13) Persuading: After all, Look, No doubt 14) Referring to the Other Person's Expectations: Actually, In fact, As a matter of fact, To tell the truth, Well 15) Summing Up

Figure 1. Discourse makers types (Dülger, 2007: 261). 
As seen in Figure 1 above, Dülger designed a comprehensive list of discourse markers based on their purposes. As a result, discourse markers are terms or phrases that represent to indicate how the present expression relates to previous discourse while also adding to the message's context. They are most effective when used at the starting of clauses.

In rundown Discourse analysis, the arrangement and perception of language and its utilization inside discussion (Bright, 1992) have centered on different parts of linguistic theory. The examinations have explored how language joins speakers and audience members, how speakers basically put together language, how language facilitates or directs our everyday exercises. Linguistics contemplates fill in as antecedents to the investigation of discourse markers (Croucher, 2004: 39).

\begin{tabular}{|c|c|c|}
\hline Form of relationships & Sentence connectors & $\begin{array}{l}\text { Position within } \\
\text { clause/Sentence }\end{array}$ \\
\hline Adding something & $\begin{array}{l}\text { Moreover; In addition; Additionally; } \\
\text { Further; Further to this; Also; } \\
\text { Besides; What is more. }\end{array}$ & Initial position \\
\hline $\begin{array}{l}\text { Making an unexpected contrast } \\
\text { (concession) }\end{array}$ & $\begin{array}{l}\text { Although; Even though; Despite the } \\
\text { fact that; In spite of the fact that; } \\
\text { Regardless of the fact that. }\end{array}$ & $\begin{array}{c}\text { Initial position } \\
\text { Starts a } \\
\text { second/ subordinate } \\
\text { clause }\end{array}$ \\
\hline Saying why something is the case & Because; Since; As; Insofar as. & $\begin{array}{c}\text { Initial position } \\
\text { Starts a } \\
\text { second/subordinate } \\
\text { clause }\end{array}$ \\
\hline $\begin{array}{l}\text { Saying what the result of } \\
\text { something is }\end{array}$ & $\begin{array}{l}\text { Therefore; Consequently; In } \\
\text { consequence; As a result; } \\
\text { Accordingly; Hence; Thus; For this } \\
\text { reason; Because of this. }\end{array}$ & Initial position \\
\hline Expressing a condition & $\begin{array}{l}\text { If; In the event of; As long as...; So } \\
\text { long as...; Provided that...; Assuming } \\
\text { that...; Given that.... }\end{array}$ & $\begin{array}{c}\text { Initial position } \\
\text { Starts a } \\
\text { second/subordinate } \\
\text { clause }\end{array}$ \\
\hline Making what you say stronger & $\begin{array}{l}\text { On the contrary; As a matter of fact; } \\
\text { In fact; Indeed. }\end{array}$ & Initial position \\
\hline
\end{tabular}

Figure 2. What are the different discourse markers that can be used? (Sharpling, 2010)

As shown in Figure 2, Sharpling (2010) was created the model of types of connection DMs. From discovered that the most popular methods of connection between concepts as well as the major component most commonly used to express these relationships are listed in the figure above. The discourse markers shown in the list are usually used at the start of a phrase or clause. This study focuses on the usage of the different DMs and finds out how sentence connectors can be replaced in order to increase variety in writing.

\subsubsection{Strategies for Corpus Linguistics}

The Corpus dissection is a portion of text validation that provides a high level of association among abstract articles. All those things are supposed when verifying notifications as human beings. Where there are few types of records, examples of the regular use of repetitive sentence structures or expressions may be found in the archives. It could well be intended to discover for turns of phrase that are quantifiably cherished or not envied by the author or by a unique combination of text, a specific variety of lexical objects, or different circumstances of conscious awareness in a vast collection of environmental publications. Corpus estimation is obviously valuable for analyzing the existence of the 
manuscript or, potentially, the inertial navigation results of other computer-controlled techniques (Atqia, et. al., 2017; Heather, 2015; Salama, 2021).

\subsubsection{AntConc}

AntConc to complete exercises that illustrated some of the most common techniques used in corpus linguistics studies (Laurence, 2006). Since AntConc might be non-instinctive to utilize, this segment quickly portrays investigation procedures accessible utilizing the corpus. This segment tells the best way to perform investigations through the Concordance, File View, Clusters/N-Gram, and Collocate tabs utilizing the Florida - New York sub-corpus. Explicit models are given with the goal that potential clients may utilize this data as a guide on the best way to utilize the corpus, and how to choose the techniques most appropriate for different inquiries (Skier \& Vibulphol, 2016).

\subsection{The Framework of the Study}

Discourse marker analysis is part of a more general discourse analysis-how $\mathrm{Ph} . \mathrm{D}$. students combine kinds, usages, and intentions to make an innate understanding of what would be written. (Schiffrin, 1987: 49) The approach shown in this study was implemented that posited by Dülger (2007), Schiffrin (1987), and Sharpling, (2010).

\subsection{Research Objectives}

A significant goal of the examination, aside from the overall depiction of the recurrence of the utilization of DMs (adding something), was to research the connection between the quantity of DMs (adding something) utilized and the quality of writing as follows:

1. To identify the general description of the frequency of use of DMs (adding something) in the Thesis' Abstracts of Ph.D. writing

2. To investigate the relationship between the number of DMs (adding something) contribute to the Thesis' Abstracts of Ph.D. writing.

\subsection{Research Questions}

The current investigation expects to recognize and evaluate the DMs (adding something) in the instructive theses' abstracts writing. It expects to examine the connection between the utilization of DMs, and the quality of writing. Also, recognize a portion of the highlights that portray Ph.D. understudies writing concerning the decision, and utilization of DMs as follows:

1. What are the most and the least frequency of the use of DMs (adding something) in the Thesis' Abstracts of Ph.D. writing?

2. How well do the use of DMs (adding something) contribute to the Thesis' Abstracts of Ph.D. writing?

3. In term of functions, what are the role of the user of the DMs (adding something) in the Thesis' Abstracts of Ph.D. writing?

\subsection{Definition of Key Terms}

1. Discourse marks are 'sticks' that are slightly linked in an arrangement, giving content are still together. Discourse is used less frequently, except when it is formal (Sharpling, 2008).

2. Form of relationships alludes to seven kinds of talk markers; Adding something, Making a differentiation between two separate things, Making a startling difference, Saying what the aftereffect of something is, Expressing a condition, and Making what you state more grounded. 
3. Adding something is a kind of talk marker used to demonstrate that we are adding something to what exactly we've just said or composed for example besides, what's more, further, moreover, father to this, furthermore, additionally, likewise, and other than.

4. Corpus refers to 108 abstracts from American leading universities.

5. AntConc is a program developed by Laurence Anthony of Waseda University, Japan. This study is used to analyze word frequencies.

6. Frequency corresponds to "the quantity of cycles or finished shifts per unit of time." all in all, recurrence implies some check per unit of time. In conduct examination, the most widely recognized proportion of recurrence has been reactions every moment. In conduct investigation, recurrence frequently gets renamed as "rate" or as "pace of reaction."

7. Abstracts, similar to all synopses, cover the primary concerns of a bit of composing. Dissimilar to leader rundowns composed for non-expert crowds, abstracts utilize a similar degree of specialized language and mastery found in the article itself. What's more, not normal for general rundowns which can be adjusted from multiple points of view to address different per users' and authors' issues, abstracts are commonly 150 to 250 words and follow set examples.

8. Quality is characterized by society in general: 'Quality is a continuous cycle of establishing and supporting connections by assessing, predicting, and meeting expressive and conclusive needs'.

\section{Method}

This investigation examinations 108 abstracts works in the field of education were chosen by purposive sampling from American top ranking universities such as Illinois State University, University of Washington, and the University of Pittsburgh. The discourse markers (adding something) from abstracts considered were gathered in elite, and beginning from the abstract no. 1 to no.108. Then each abstract was identified and quantified for DMs. Those abstracts have analyzed the frequencies of DMs: moreover, further, furthermore, in addition, additionally, alternatively, also, what is more, besides, by "AntConc" Program. (AntConc is a multifunctional concordancer that raises funds for several sophisticated congruence design elements (Laurence, 2006). It is developed by Laurence Anthony of Waseda University, Japan).

Then each DM was determined to find their functions in the contexts and relationship between the frequencies of use of DMs in the Thesis' Abstracts of Ph.D. writing. The research method consists of data sources. The data collection, research tools, and data analysis are described as follows:

\subsection{Instrument}

In this research, AntConc Version 3.4.4 (Laurence, 2014) was used to analyze the frequency and classification of words in the archives of discourse markers research. AntConc was developed in several versions by Anthony Laurence and AntConc. It is one of the programs used in the analysis of the language archives most after the program "corpus.byu.edu" (Laurence, 2013) AntConc is a freeware program that is fast and easy to use (Laurence, 2013), so the researchers chose AntConc to determine the frequency of discourse markers (adding something) in the data warehouse.

\subsection{Data collection procedures}

The researchers downloaded a total of 108 published research papers of Ph.D. students in the field of education from top rank universities in the United States by using a purposive sampling method. The past 5 years (2015 - 2019) in order to obtain up-to-date information and publication of 108 articles each year with different topics. After that, the research team converted the data files from .pdf extension to .txt extension because AntConc (Laurence, 2014) could only read files with .txt extension, 
and then cut the components of research articles such as bibliography, reference documents, region, append footnote, caption all of the research articles were left for abstracts only. The data files were saved to 108 files from 108 topics for research purposes.

\subsection{Data analysis}

The discourse markers (adding something) from abstracts considered were gathered in elite, and beginning from the abstract no.1 to no.108. Then each abstract was identified and quantified for DMs. Those abstracts have analyzed the frequencies of DMs: moreover, further, furthermore, in addition, additionally, alternatively, also, what is more, besides, by "AntConc" Program. The researchers analyzed the data by adding 108 files to AntConc to determine the frequency of writing "abstracts" of $\mathrm{Ph} . \mathrm{D}$. students. In the field of education from the language repository defined in the research (adding something), when all the terms have been defined, then create a list of the highest and lowest frequency (adding something).

\section{Results}

Table 1. Frequencies of DMs (Adding something) usage, conducted from 108 Ph.D. thesis' Abstracts writing

\begin{tabular}{lcccc}
\hline \multicolumn{1}{c}{$\begin{array}{c}\text { DMs (Adding } \\
\text { something) }\end{array}$} & $\begin{array}{c}\text { Frequencies } \\
\text { analyzed by } \\
\text { AntConc }\end{array}$ & $\begin{array}{c}\text { Frequencies of } \\
\text { DMs }\end{array}$ & $\begin{array}{c}\text { Percentages } \\
\text { of DMs are } \\
\text { used }\end{array}$ & $\begin{array}{c}\text { Position within } \\
\text { clause/sentence }\end{array}$ \\
\hline Also & 82 & 3 & 9.09 \\
Further & 20 & 5 & 15.15 & \\
In addition & 13 & 13 & 39.39 & Initial position \\
furthermore & 5 & 5 & 15.15 & 12.12 \\
Moreover & 4 & 4 & 9.09 & \\
Additionally & 3 & 3 & 0 & \\
Besides & 0 & 0 & 0 & \\
What is more & 0 & 0 & 100 & \\
\hline \multicolumn{1}{c}{ Total } & 127 & 33 & 0 \\
\hline
\end{tabular}

As shown in Table 1, the "AntConc" software was used to analyze the adding something, DMs data for this article, and it was discovered that Furthermore, the results of this article are the most widely used marker (39.39\%), followed by "In addition" and "Additionally" markers, each of which is $(15.15 \%)$, "in addition" markers (12.12 \% t), "also" and "additionally" markers, each of which is (9.09 $\%)$. The least common ones. In the random abstracts, the phrases "what is more" and "in addition to" markers did not appear (0\%). In certain instances, the terms "also and further" were classified as DMs, but the functions were not DMs because they were not at the initial location.

\subsection{Discourse markers (Adding something)}

In this article, the DMs (Adding something) which conducted from $108 \mathrm{Ph} . \mathrm{D}$. thesis' abstracts writing which found that the authors were giving additional information when they write. The additional details must be relevant to the first in some way. The following discourse markers are always used at the start of a sentence to indicate that Ph.D. students about to offer more detail, and can 
be used in more formal situations: In addition, Moreover, in addition to this/that, What is more. If consider the fact that Ph.D. students use the DMs to provide supplementary detail. Thus assumes that if the initial statement was optimistic, or more optimistic details would be added, and simultaneously.

\section{Discussion}

The present results obtained from the analyses of 108 the Ph.D. thesis' abstracts writing did give answers to the diverse exploration addresses defined.

Research Question 1: What are the most and the least frequency of the use of DMs (adding something) in the Ph.D. Thesis' Abstracts writing?

In the first step, those abstracts have analyzed the frequencies of DMs: moreover, further, furthermore, in addition, additionally, alternatively, also, what is more, besides, by "Ant Conc" Program. Then following by calculating the frequencies of each DM which shows how often each is employed in the abstracts.

Table 1 above shows that the subjects in this examination utilized an assortment of DMs (adding something) for certain markers utilized more regularly than others. In addition, the marker was the most frequently employed (39.39\%), followed by further and furthermore markers, each of them $(15.15 \%)$, moreover marker (12.12\%), also and additionally markers, each of them (9.09\%) and what is more, besides markers, they have not appeared in the random abstracts $(0 \%)$. The broad utilization of adding something markers has been clarified on the grounds that theoretical composition, when all is said in done, requires the elaboration of thoughts which relies upon the title.

Research Question 2: How well does the use of DMs (adding something) contribute to the Thesis' Abstracts of Ph.D. writing?

This is accomplished using discourse markers. To connect recently expressed thoughts with novel thoughts, the essayist for the most part utilizes discourse markers and reworded rehashing of the past section's substance. Discourse markers (adding something) are words that sign of relationship for option, and summation. They are utilized to associate the old thoughts with the new ones. They additionally direct the peruser toward various sorts of connections in the thoughts being introduced. Discourse markers are valuable since they help set up the peruser for what will continue in the content, and accordingly encourages understanding.

The general use of DMs (adding something) in the educational theses' abstracts writing is a variety to indicate what the writers have written. The most common use of discourse shows what the writers are 'adding something' firmly identified with what has preceded. The writers generally place also before the 'additional point'

Other discourse markers have a comparative capacity however are utilized in more proper settings. The writers use moreover, furthermore, and in addition to considering introducing almost all of two or even more considerable components of the abstracts. These markers frequently start in another sentence.

Besides generally acquaints data which adds weight with what the writers have just composed, yet in various sort of point. The writers regularly utilized besides when they are convincing, offering guidance, or contending something.

At the point when the writers have finished their first draft, it is important to amend it, potentially a few times. The primary update concerns substance and association. This, thus, can be separated into stages. 
On the off chance that the essayists have arranged their edited abstracts well, all the central matters ought to apply to the succession of their discoveries. In any case, there might be some supporting focuses, subtleties, and models which are not actually fundamental. Readers are continually paying special mind to cushion - material which isn't actually significant yet has been placed in to make the modified works longer and bring it up to the base number of words. On the off chance that something doesn't look significant, cut it out.

Add detail that is important to completely uphold, or explain a point the writers have made. Each primary thought should be supported up with legitimate contention or proof of the finding. In the event that a portion of the contentions appears to be somewhat frail, return to the notes, and if vital the first sources, to discover the supporting point of interest. It might likewise be important to explain a portion of the essayists' thoughts by additional clarification or definition. Ensure that they have not utilized terms, (for example, and so on) in a particularly broad way that the peruser may ask "what does he/she truly mean here?" Ask a companion to read the edited abstracts so they can advise you if there are any focuses which they don't comprehend.

When in doubt, each abstract ought to have one, which is communicated by its theme sentence (generally the primary sentence of the passage). Albeit a couple of lines, passages are sporadically conceivable, they ought to when all is said in done be stayed away from. Where conceivable, consolidate short sections, and if fundamental add a couple of words to go along with them (e.g., "In addition...", "A further point is that ..."). Then again, if a passage takes up the majority of the page, it is most likely a smart thought to split it up into a few more limited sections.

Research Question 3: What is the role of the use of the DMs (adding something) in the Thesis' Abstracts of Ph.D. writing?

\section{As Table 1 above shows that;}

1. There are lots of DMs, adding something, the writers use only some of them when writing the abstracts.

2. Some words determined as DMs, but the functions were not DMs because they are not at the initial position: "also" and "further".

also modifier (adv.),conjunction

further modifier(adj., $a d v$.)

\section{Example 1:}

- Also, this investigation found that Illinois directors saw the Illinois administrator authority content territory principles information markers to be either significant or to some degree significant more often than not.

- The study also found that substance abuse and disciplinary problems were among the critical problems causing students to drop out of school in recent years.

\section{Example 2:}

1. Further, preparation programs could be significantly strengthened by educating administrators in differentiated curriculum and teaching that can meet the needs of all students.

2. This research further develops scholarship in educational administration, politics of education, and education policy analysis.

3." In addition", "Furthermore", "Moreover" and "Additionally", were mostly found in the middle of the end of the paragraph. Also, they are usually shown in long sentences. 


\section{Example 3:}

This study sought to expand our understandings of the challenges that female leaders face in the educational arena as well as their contributions. Regarding the intersection of the participants' gender and the male-constructed high school principalship, the study uncovered seven emerging themes. These included: the image of the high school principal, rites of passage and proving oneself, limits to proving oneself/arm-flexing and intimidation, being put on watch, invisible networks made visible for gaining acceptance, mentoring for leadership development, and silence and the rules. In addition, the study illustrated varied leadership perspectives offered by the participants depicted by the following themes: relationships are central, community building for collective capacity, open doors, and open ears: attuned listening, and acknowledgment, emotional investments and nurturing reap returns, dignity and respect are foundational to leadership that nurtures, instruction must prevail, and children are the focus.

Furthermore, it was discovered that specific connections existed among individual as well as locale segment factors and the view of Illinois directors concerning the level of significance of the Illinois administration content zone stands and information demonstrates.

Moreover, they exhibited ground breaking administration practices that included gathering inborn necessities of adherents, visionary initiative, building collective school societies, and placing educators in jobs of instructional authority.

Additionally, statistically significant but low positive relationships between the subjects' errordetection performances and their ratings of levels of passage understanding were found

\section{Conclusions}

In instructional writing, discourse markers are a big problem. In prose, markers create continuity and coherence and generate ideas for the readers meaningfully. The textual material must be illogically constructed, and within the sentences and paragraphs, there could be no progression. There can be various forms of discourse markers, and a clear meaning is conveyed by each one. Discourse Indicators, as integral additives in exceptional literature. In promoting principles of comprehension in the text, this importance lies. This means uploading the words and sentences with these markers. Discourse Markers cause the float of writing to go to the flow with no disturbance. In educational abstracts writing, markers are essential and they must be applied best when appropriate. This research examined the kinds, frequencies of use, and functions of Discourse Markers (DMs) that centered on the addition form, i.e. "in addition, and what is more"-used in the abstracts of the Ph.D. educational theses. The research was compiled, with a total of 108 abstracts were chosen by purposive sampling from American top-ranking universities.

The "AntConc" software to analyze a quantitative and qualitative process in this paper is the method used for the dominant one. Furthermore, the most commonly used marker (39.39\%) is the results of this article, followed by "In addition" Additionally" markers, each of them (15.15\%), "in addition" markers (12.12\%), "also" and "additionally" markers, each of them (9.09\%) being the least (9.09\%). The least common ones. In the random abstracts, the phrases "what is more" and "in addition to" markers did not appear (0\%). In certain instances, the terms "also and further" were classified as DMs, but the functions were not DMs because they were not at the initial location DMs impact the writing expertise of the subject and the float of concepts in a bendy style. Jalilifar (2008) finds out that "DMs help perceive top and poor writings in addition to various textual characteristics, and more specifically, the best is tapped using well-functioned DMs." In addition, the guides to improving written coherence, and cohesion are these markers. While they are misplaced or underused by these authors. All of that is indicated by Aidinlou \& Shahrokhi Mehr (2012), who argue whether "on the one 
hand", it is highly interrelated to understanding DMs, and united family members, and the normal production of textual content.

This paper, in short, makes a big contribution to the study of second languages. This emphasizes the importance of discourse markers in improving the meaning of written work. Then there are a few clues obtained from this report. In academic writing, the students were encouraged to take a look at how to practice Discourse Markers exactly. The characteristics of these markers should be made clear to university students at all levels, especially at the Ph.D. level. They ought to have the basic facts of the Discourse Markers, and should try in the given sense while using them. Eventually, connection and precision are factors that must be taken into consideration when using the markers at the same time effectively. The pointers were aimed at embellishing the essential field of language analysis. It was already hoped that this could resource and include a few useful innovative and prescient discourse indicators for other scholars, from which further studies and analysis can be carried out.

\section{Implications for Research and Practice}

The finding of this research would be a benefit to the learners who study writing English or writing abstracts as following:

1. The writers could write the abstracts better when they understand how to use DMs and their functions.

2. Even without the convenience of the DMs, a book would not seem to have been straightforwardly established, and the affiliation respectively dissimilarities and excerpts would not have been conscience.

3. Some DMs were ignored, e.g. besides, what is more, etc. This in turn leads us to observe that American Ph.D. students who have a high writing proficiency are capable of using a large form of DMs rather than using the general ones.

\section{Ethics Committee Approval}

The authors confirm that the study does not need ethics committee approval according to the research integrity rules in their country. (Date of Confirmation: 09.01.2021)

\section{Acknowledgments}

I would like to show my thankfulness to the team of English Program Supervisors at Suan Dusit University, who have motivated me all across the project. I would like to also thank my family, and friends who encouraged me and provided me with a profound understanding of the research. I would really like to express my sincere appreciation to the Dean of the Faculty of Humanities and Social Sciences, in particular to the President of Suan Dusit University who promoted and authorized the project for the writing journal to be accomplished.

\section{References}

Aidinlou, N. A., \& Shahrokhi Mehr, H. (2012). The Effect of Discourse Markers Instruction on EFL Learners' Writing. World Journal of Education, 2(2), 10-16.

Aijmer, K. (2002). English discourse particles: Evidence from a corpus. Studies in Corpus Linguistics. Amsterdam and Philadelphia: John Benjamins. 
Aziz, A., Mahmood, M.A., Ahmad, S., \& Akbar, N. (2021). A corpus-based study of genre-specific discourse: M.A. TEFL thesis abstracts. Journal of Language and Linguistic Studies, 17(Special Issue 2), 884-898.

Atqia, A., Dewi, K., Rizal, B. B., \& Nashrul, H. (2017). WatsaQ: Repository of Al Hadith in Bahasa (Case Study: Hadith Bukhari). Yogyakarta, Indonesia, Proceeding of the Electrical Engineering Computer Science and Informatics, 4(1), 21-24.

Blakemore, D. (1987). Semantic Constraints on Relevance. Oxford: Blackwell.

Blakemore, D. (1988). "So as a constraint on relevance". In R. Kemson, ed., Mental representations: The Interface between Language and Reality. Cambridge: Cambridge University Press, 183-195.

Blakemore, D. (1992). Understanding Utterance. Oxford: Blackwell.

Bright, W. (ed.) (1992). International Encyclopedia of Linguistics. New York: Oxford University Press.

Carter, R., \& McCarthy, M. (2006). Cambridge grammar of English: A comprehensive guide: Spoken and written English grammar and usage. Cambridge, UK: CUP.

Croucher, S. M. (2004). Like, You Know, What I'm Saying: A Study of Discourse Marker Frequency in Extemporaneous and Impromptu Speaking. The University of Oklahoma.

Csilla, I. D. (2010). On the Status of Discourse Markers. Acta Linguistica Hungarica, 57(1), 3-28.

Dülger, O. (2007). Discourse markers in writing. Selçuk Üniversitesi Sosyal Bilimler Enstitüsü Dergisi, 18, 257-270.

Erman, B. (1987). Pragmatic expressions in English: A study of "you know", "you see", and "I mean" in face-to-face conversation. Acta Universitatis Stockholmiensis, Stockholm Studies in English 69. Stockholm: Almqvist and Wiksell.

Fraser, B. (1988). Types of English discourse markers. Acta Linguistica Hungarica, 38, 19-33.

Fraser, B. (1990). An approach to discourse markers. Journal of Pragmatics, 14, 383-395.

Fraser, B. (1996). Pragmatic markers. Pragmatics, 6(2), 167-190.

Fraser, B. (1999). What are discourse markers?. Journal of Pragmatics, 31, 931-952.

Halliday, M.A.K., \& Hasan, R. (1976). Cohesion in English. London: Longman.

Hansen, Maj-Britt. M. (1998a). The function of discourse particles. A study with special reference to spoken Standard French. Amsterdam \& Philadelphia: John Benjamins.

Heather, F. (2015). Corpus Analysis with Antconc. The Programming Historian.

Jalilifar, A. (2008). Discourse Markers in Composition Writings: The Case of Iranian Learners of English as a Foreign Language. English Language Teaching, 1(2), 114-122.

Laurence, A. (2006). Concordance with AntConc: An introduction to tools and techniques in corpus linguistics. Center for English Language Education in Science and Engineering, Waseda University.

Laurence, A. (2013). Developing AntConc for a new generation of corpus linguists [PowerPoint Slides]. Retrieved from http://cass.lancs.ac.uk/wpcontent/uploads/2014/10/ aacl_2014_corpus_tools_brainstorming_printing.pdf 
Laurence, A. (2014). AntConc (Version 3.4.4) Retrieved 21 November 2020, from http://www.laurenceanthony.net/software/antconc/

Lenk, U. (1998). Marking discourse coherence: Functions of discourse markers in spoken English (Vol.15). Gunter Narr Verlag.

Levinson, S. C. (1983). Pragmatics. Cambridge: Cambridge University Press.

Luke, K. K. (1990). Utterance Particles in Cantonese Conversation. Amsterdam/Philadelphia: John Benjamins Publishing Company.

Kempson, R., Meyer-Viol, W., \& Gabbay, D. (2001). Dynamic Syntax. The Flow of Language Understanding. Blackwell.

Mari, C. C., Begona, B. F., \& Ma, L. G. (2010). Corpus-Based Approaches to the English Language Teaching. Wolfgang Teubert, University of Birmingham, and Michaela Mahlberg, University of Liverpool: Continuum International Publishing Group.

Quirk, R., Greenbaum, S., Leech, G. \& Svartvik, J. (1985). A comprehensive grammar of the English language. London: Longman.

Redeker, G. (1991). Review article: Linguistic markers of discourse structure. Linguistics, 29(6), 1139-1172.

Romero, T. J. (1997). Your attention, please: Pragmatic mechanisms to obtain the addressee's attention in English and Spanish conversations. Journal of Pragmatics, 28, 205-221.

Salama, Amir H.Y. (2021). A methodological synergy of dramatic discourse analysis and corpus linguistics: From the discourse of US Presidents to Trump's 2016 Orlando speech. Journal of Language and Linguistic Studies, 17(Special Issue 2), 752-772.

Schiffrin, D. (1987). Discourse markers. Cambridge: Cambridge University Press.

Schourup, L. C. (1985). Common discourse particles in English conversations: "like”, "well”, “y'know". New York and London: Garland.

Sharpling, G. (2010). Differences between Spoken and Written Discourse. The University of Warwick, Coventry, United Kingdom.

Skier, J., \& Vibulphol, J. (2016). Development and Use of a Corpus Tailored for Legal English Learning. PASAA, 52(July - December), 237-254.

Sukhothai Thammathirat Open University. (2005). The Mechanics of Writing. Retrieved 21 November 2020, from https://www.stou.ac.th/schools/sla/englishwriting/cd-rom/Module6/Index6.htm

Vivian, H. (1969). Teaching Logical Relationships in Written Discourse. TESOL Quarterly, (December), 291-296.

\section{AUTHORS BIODATA}

Suna Kunghai, Lecturer, English Program, Faculty of Humanities and Social Sciences, Suan Dusit, University. Ph.D. candidate in Linguistics, Department of Foreign Language, Mahachulalongkornrajavidhayalaya University, Thailand. Suna Kunghair completed her Diploma School Education \& Japanese Certificate from Shizuoka University, with Japanese Government Scholarship, Japan, and Master's degree in Applied Linguistics at the University of New South Wales, Australia. She had experience in working as an External Relation Officer and an Education Officer with the Office of the Basic Education Commission, Ministry of Education, Bangkok for more than ten years. Then she started teaching English as a foreign language at Suan Dusit University, 
Bangkok in 2005. Her research interests include teaching English reading, comparative English textbooks in Thailand to foreign country and Linguistics: Discourse Analysis.

Chaleomkiet Yenphech, Buriram Rajabhat, University. Chaleomkiet Yenphech is currently a lecturer in Humanities and Social Sciences, Buriram Rajabhat University, Thailand. He obtained his master's degree with high distinction in Teaching English from Ramkhamheang University, Bangkok Metropolis. His research interests include language in factor analysis, classroom contexts, and technology-based activities. He has presented papers at international conferences both home and abroad, published articles and papers in various journals. Ph.D. candidate in Linguistics, Department of Foreign Language, Mahachulalongkornrajavidhayalaya University, Thailand. 